\title{
'Wepster' Hazelnut
}

\author{
Shawn A. Mehlenbacher ${ }^{1}$, David C. Smith, and Rebecca L. McCluskey \\ Department of Horticulture, 4017 Agricultural and Life Sciences Building, \\ Oregon State University, Corvallis, OR 97331
}

Additional index words. Anisogramma anomala, Corylus avellana, eastern filbert blight, filbert, nut breeding

\begin{abstract}
'Wepster' is a new hazelnut (Corylus avellana $\mathrm{L}$.) cultivar for the blanched kernel market. It was released by the Oregon Agricultural Experiment Station in Jan. 2013 as an alternative to 'Yamhill'. It combines complete resistance to eastern filbert blight (EFB) caused by the fungus Anisogramma anomala (Peck) E. Müller with high nut yield, small nut size, early nut maturity, very good kernel quality, and high tree vigor. 'Wepster' is recommended for Oregon's Willamette Valley and other areas with a similar climate.
\end{abstract}

\section{Origin}

'Wepster', tested as OSU 894.030, resulted from a cross of 'Tonda Pacifica' (Mehlenbacher et al., 2011b) $\times$ OSU 440.005 made in 1997 by Shawn A. Mehlenbacher and David C. Smith (Fig. 1). The pedigree includes germplasm from Italy ('Tonda Gentile delle Langhe', 'Montebello'), Spain ('Barcelona'), England ('Daviana'), Turkey ('Tombul Ghiaghli', 'Extra Ghiaghli'), and the Pacific Northwestern United States ('Gasaway'). Hybrid seeds from the controlled cross were harvested in Aug. 1997, stratified, and the resulting seedlings grown in a glasshouse during the summer of 1998. From this cross, 233 seedlings were planted in the field in Oct. 1998. The designation OSU 894.030 indicates the row and tree location of the original seedling at the Smith Horticultural Research Farm in Corvallis, OR. Nuts were first observed on the original seedling in Sept. 2001. There were very few nuts, and they were not harvested. Nuts were harvested from the original seedling tree and evaluated the next 4 years (2002$05)$. OSU 894.030 was propagated by tie-off layerage of the suckers in the summer beginning in 2004. The rooted layers were lined out in a nursery row the year after layerage and used to plant two replicated yield trials the next spring (2006). Four trees of each genotype were planted in the first trial and seven trees of each in the second trial. Both trials were located at the Smith Horticulture Research Farm and planted as randomized

\footnotetext{
The OSU hazelnut breeding program is supported by State, Hatch Act and Oregon Hazelnut Commission funds. Additional support was provided by a specific cooperative agreement with the U.S. Dept. of Agriculture.

A technical paper of the Oregon Agricultural Experiment Station.

${ }^{1}$ To whom reprint requests should be addressed; e-mailmehlenbs@hort.oregonstate.edu.
}

complete block designs with a single tree of each genotype in each block. EFB-resistant cultivars Jefferson (Mehlenbacher et al., 2011), Santiam (Mehlenbacher et al., 2007), and Yamhill (Mehlenbacher et al., 2009) and several additional numbered selections were included in both trials. Susceptible control cultivars Barcelona, Lewis (Mehlenbacher et al., 2000), and Clark (Mehlenbacher et al., 2001) were planted on the same date in a trial adjacent to the first trial. The name 'Wepster' honors the contributions of the Wepster family to the Oregon hazelnut industry and the Oregon State University (OSU) hazelnut breeding program. Jan Wepster, his wife Linda, and his father Bert were active in the Oregon hazelnut industry for many years. Jan Wepster was instrumental in the creation of an endowed professorship at the OSU Foundation to support the breeding program.

\section{Description}

Trunk diameter was measured $30 \mathrm{~cm}$ above the soil line at the end of the growing season, in Dec. 2012, and used to calculate trunk cross-sectional area (TCA). TCA provides an estimate of tree size. In the first trial (Table 1), trees of 'Wepster' $\left(84.4 \mathrm{~cm}^{2}\right)$ were the largest in the trial and $106 \%$ of 'Jefferson'. TCA of 'Wepster' was intermediate between 'Lewis' $\left(73.0 \mathrm{~cm}^{2}\right)$ and the vigorous standard 'Barcelona' $\left(97.8 \mathrm{~cm}^{2}\right)$ in adjacent rows planted at the same time. Total nut yield per tree (third to seventh leaf) was $25.91 \mathrm{~kg}$ for 'Wepster' vs. $19.46 \mathrm{~kg}$ for 'Yamhill' or $133 \%$ of the control. Nut yields of 'Wepster' were high in each year of the trial. In contrast, the very high nut yields of 'Yamhill' in 2011 resulted in poorly filled nuts and kernels that were not marketable. The stressed 'Yamhill' trees had low nut yields in 2012. Nut yield efficiency, which adjusts for differences in tree size, was higher for 'Wepster' $\left(0.306 \mathrm{~kg} \cdot \mathrm{cm}^{-2}\right)$

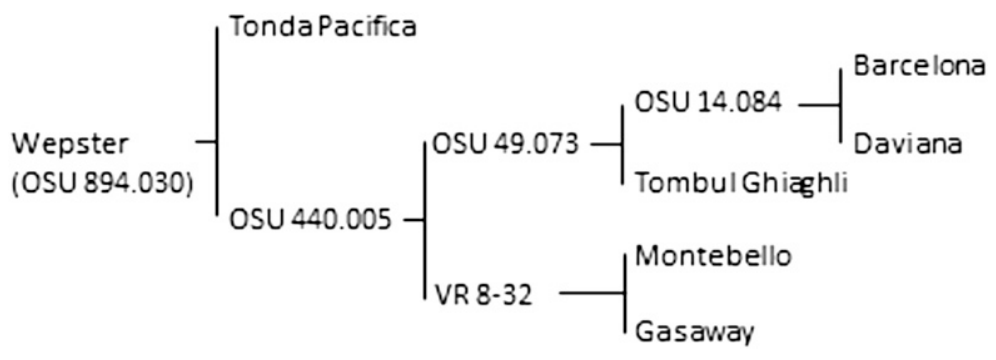

Fig. 1. Pedigree of 'Wepster' hazelnut. than for 'Yamhill' $\left(0.288 \mathrm{~kg} \cdot \mathrm{cm}^{-2}\right)$ but the difference was not statistically significant. Kernel percentage (the ratio of kernel weight to nut weight) for 'Wepster' $(46.6 \%)$ is similar to 'Yamhill' (46.2\%) and higher than 'Barcelona' (typically 43\%) (Table 2). Yields of kernels per acre would be much higher for 'Wepster' than 'Barcelona'. In the second trial (Table 1), TCA of 'Wepster' was $116 \%$ of 'Jefferson', 126\% of 'Yamhill', and slightly higher than 'Sacajawea'. Total nut yield per tree was $19.67 \mathrm{~kg}$, which is not significantly different from 'Jefferson' or 'Yamhill'. Nut yield efficiency of 'Wepster' $\left(0.198 \mathrm{~kg} \cdot \mathrm{cm}^{-2}\right)$ was lower than 'Jefferson' and 'Yamhill' and similar to 'Sacajawea'. Kernel percentage was based on well-filled nuts in the first trial and field-run nuts in the second. Kernel percentage is thus higher in the first trial than in the second. 'Wepster' trees are vigorous, globose in shape (Fig. 2), and easy to train as single-trunk trees and manage in an orchard. Occasional pruning is desirable to allow sunlight to penetrate the canopy. In contrast, the low vigor and spreading habit of 'Yamhill' makes it difficult for some growers to manage and for sweepers and harvesters to reach under the tree canopy at harvest time. In Oregon, orchards of the vigorous 'Barcelona' are planted at a spacing of $6 \times 6 \mathrm{~m}$. This spacing is also appropriate for 'Wepster'.

The nuts of 'Wepster' are borne in clusters of three in husks approximately twice as long as the nuts (Fig. 3). The husks are slit down the side and flare open as they dry at maturity. Approximately $95 \%$ of the nuts fall free of the husk at maturity (range, $80 \%$ to $99 \%$ ). The other nuts come out of the husks as they move through the harvester. Harvest date is estimated to be $7 \mathrm{~d}$ before 'Barcelona', allowing 'Wepster' nuts to be harvested before the start of the rainy season in most years. When mature, the shells are light tan in color on the sides but greenish at the apical end. Shell color changes to light tan as the nuts lie on the ground.

'Wepster' nuts are small, the same size as 'Yamhill' (Table 2). Percent kernel (44\% to $47 \%$ ) is similar to 'Yamhill' (46\%) and higher than 'Barcelona' (43\%). On the kernel market, major customers are confectioners and bakers, and a kernel diameter of 11 to $13 \mathrm{~mm}$ is considered ideal. 'Wepster' kernels meet this requirement, whereas the large nuts of 'Jefferson' are suited to the in-shell market. The nut shape is round, which is essential for sizing and cracking. Nut size and shape are very uniform. 
Table 1. Nut yields, trunk cross-sectional area (TCA), yield efficiency, and bud mite ratings of 'Wepster' and other hazelnut cultivars and selections in two trials planted in 2006.

\begin{tabular}{|c|c|c|c|c|c|c|c|c|c|}
\hline \multirow[b]{2}{*}{ Cultivar } & \multicolumn{6}{|c|}{ Nut yield $(\mathrm{kg} / \text { tree })^{\mathrm{z}}$} & \multirow[b]{2}{*}{$\mathrm{TCA}^{\mathrm{y}}\left(\mathrm{cm}^{2}\right)$} & \multirow[b]{2}{*}{ Yield efficiency ${ }^{\mathrm{x}}\left(\mathrm{kg} \cdot \mathrm{cm}^{-2}\right)$} & \multirow[b]{2}{*}{ Bud mite rating" } \\
\hline & $\overline{2008}$ & 2009 & 2010 & 2011 & 2012 & Total & & & \\
\hline OSU 834.018 & 0.16 & 1.86 & 3.00 & 5.63 & 6.30 & 16.95 & 66.6 & 0.254 & 2.2 \\
\hline OSU 879.031 & 0.15 & 1.20 & 2.40 & 6.03 & 5.51 & 15.28 & 67.3 & 0.227 & 2.6 \\
\hline OSU 880.054 & 0.16 & 1.53 & 1.80 & 4.06 & 3.72 & 11.27 & 54.6 & 0.207 & 1.2 \\
\hline Jefferson & 0.40 & 4.08 & 3.14 & 8.30 & 6.82 & 22.74 & 80.0 & 0.285 & 1.1 \\
\hline Santiam & 0.22 & 1.80 & 3.90 & 6.92 & 6.27 & 19.11 & 64.4 & 0.296 & 2.4 \\
\hline $\operatorname{LSD}(0.05)$ & 0.17 & 0.58 & 1.02 & 1.40 & 1.79 & 3.69 & 11.7 & 0.046 & 0.5 \\
\hline \multicolumn{10}{|c|}{ Second trial $(n=7)$} \\
\hline OSU 833.082 & 0.71 & 2.6 & 2.25 & 5.95 & 2.46 & 13.97 & 68.1 & 0.205 & - \\
\hline OSU 879.031 & 0.31 & 1.42 & 2.13 & 5.17 & 6.54 & 15.58 & 87.2 & 0.179 & - \\
\hline OSU 880.027 & 0.29 & 1.13 & 2.44 & 6.54 & 6.71 & 17.11 & 86.9 & 0.198 & - \\
\hline OSU 881.078 & 0.23 & 1.08 & 2.08 & 5.08 & 6.67 & 15.15 & 112.4 & 0.135 & - \\
\hline Wepster & 0.24 & 1.56 & 2.56 & 6.62 & 8.68 & 19.67 & 99.2 & 0.198 & - \\
\hline Yamhill & 0.78 & 2.79 & 3.88 & 7.34 & 4.94 & 19.73 & 78.5 & 0.249 & - \\
\hline York & 0.41 & 1.52 & 2.48 & 6.13 & 4.42 & 14.97 & 85.6 & 0.175 & - \\
\hline LSD $(0.05)$ & 0.17 & 0.55 & 0.75 & 0.89 & 1.26 & 2.62 & 10.4 & 0.027 & - \\
\hline
\end{tabular}

${ }^{2}$ Mean nut yields for four trees in the first trial and seven trees in the second trial.

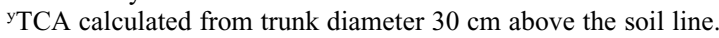

${ }^{x}$ Yield efficiency $=$ total nut yield/TCA.

${ }^{\text {w} S u s c e p t i b i l i t y ~ t o ~ b u d ~ m i t e ~(p r i m a r i l y ~ P h y t o p t u s ~ a v e l l a n a e) ~ r a t e d ~ a n n u a l l y ~ f o r ~} 5$ years in the first trial. Scale 1 (no blasted buds) to 5 (many blasted buds). LSD $=$ least significant difference.

Table 2. Nut weight, kernel weight, kernel percentage, ratings for fiber and pellicle removal, and frequency of nut and kernel defects for 'Wepster' and other hazelnut cultivars and selections in two trials planted in 2006.

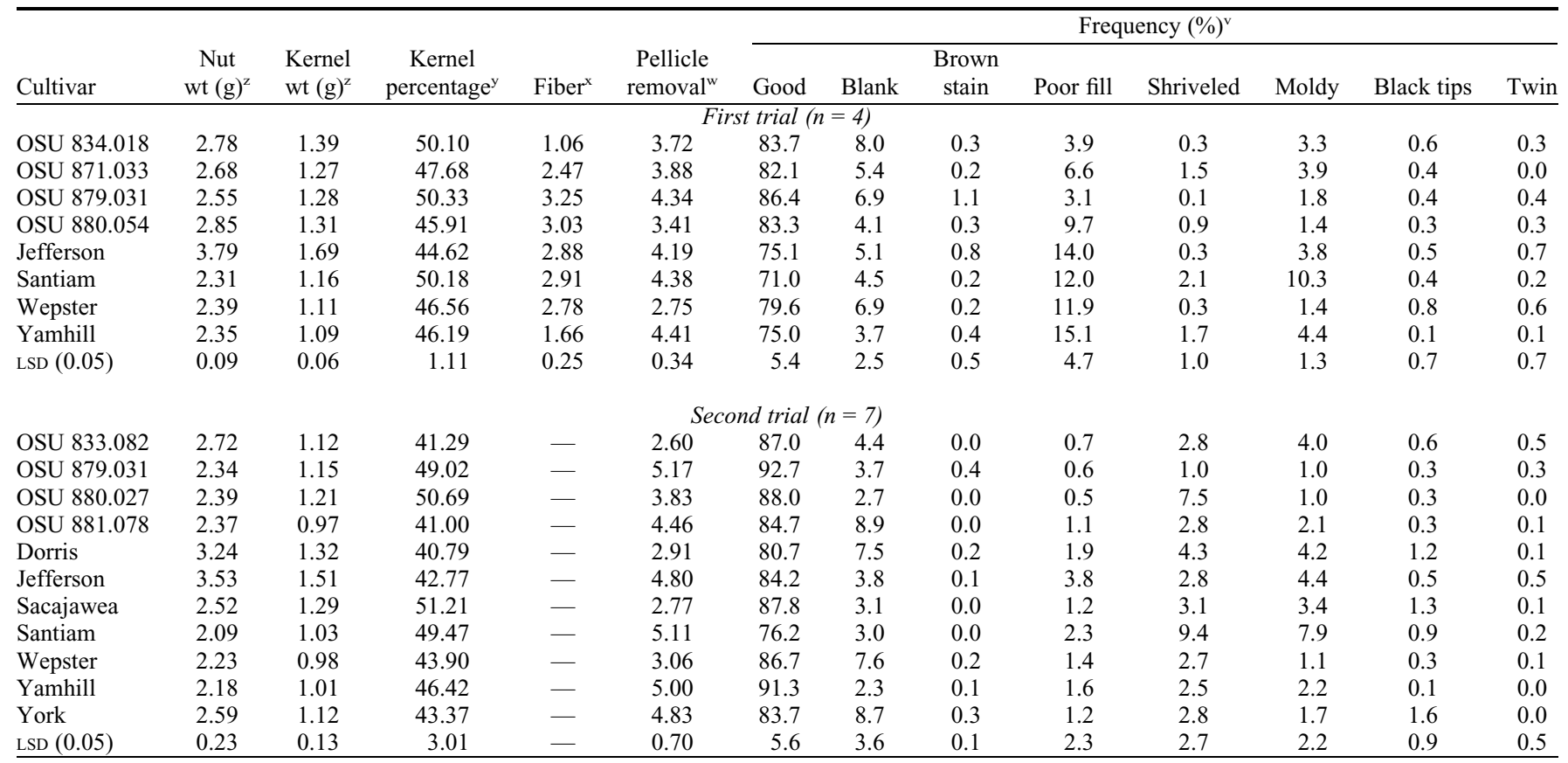

${ }^{2}$ Means for nut weight and kernel weight for 5 years (2008-12). Two 10-nut samples per tree in the first trial and one 100-nut sample per tree in the second trial.

${ }^{\mathrm{y}}$ Kernel percentage $=$ kernel weight/nut weight.

${ }^{x}$ Fiber on pellicle rated from 1 (none) to 4 (much).

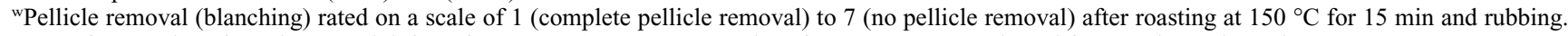

${ }^{\mathrm{v}}$ Mean frequencies of good nuts and defects for 5 years (2008-12). Samples of 100 nuts were evaluated from each tree in each year.

LSD $=$ least significant difference.

The raw kernels are attractive and have a light brown pellicle with a moderate amount of attached fiber. Most of the pellicle is removed from the kernels with dry heat in the blanching process (Fig. 4), and blanching ratings are better than 'Yamhill'. Kernel texture, flavor, and aroma are very good and acceptable for use in baked goods and chocolate products.
'Wepster' produced fewer nut and kernel defects and more good kernels in the first trial than did 'Barcelona' in adjacent rows (data not shown). Many differences among selections in 

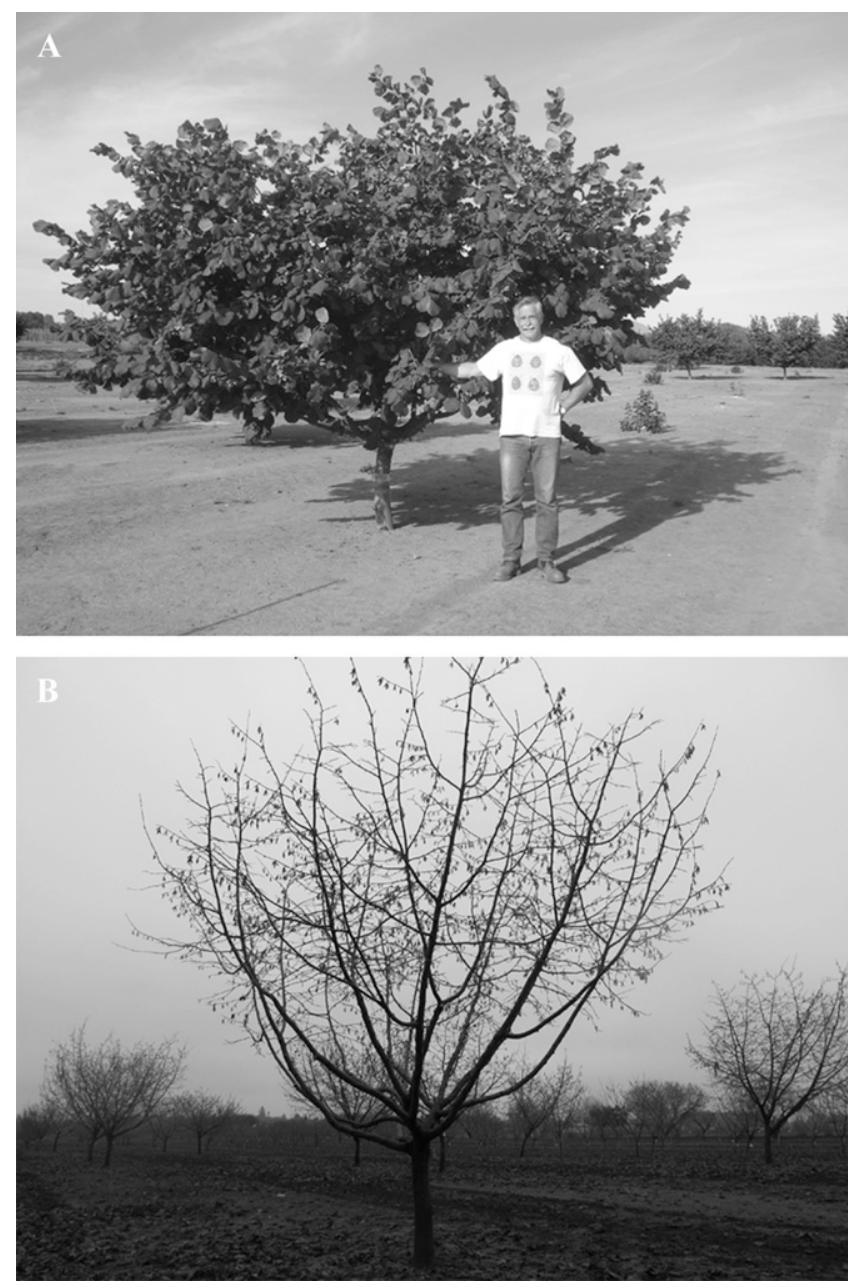

Fig. 2. Tree of 'Wepster' hazelnut in summer (A) and winter (B). the two trials (Table 2) lacked statistical significance because of the small number of replications. The frequency of moldy kernels in 'Wepster' was very low ( $1.4 \%)$, in contrast to 'Yamhill' (4.4\%) and 'Santiam' $(10.3 \%)$. Kernel mold is a problem in 'Lewis' and 'Santiam', particularly when weather is cool and wet in spring and early summer. The frequency of poorly filled nuts (average $11.9 \%$ ) is low when the heavy cropload is considered. Even in 2011, when croploads were very heavy, the kernels of 'Wepster' were marketable. In contrast, that year the very heavy crops on 'Yamhill' in the first trial resulted in very poor fill and unmarketable kernels. Nut and kernel data from the second trial were similar to those in the first trial, and no major defect problems were seen in 'Wepster'.

'Wepster' trees set a moderate to high number of catkins that shed copious amounts of pollen in midseason with 'York', 'Gamma', and 'Yamhill'. Pollen has been collected and used in several controlled pollinations, and both quantity and viability appear to be very good. Fluorescence microscopy identified incompatibility alleles $S_{1}$ and $S_{2}$ in 'Wepster', the same as in 'Barcelona' and 'Tonda Pacifica'. Both alleles are expressed in the females, but only $S_{1}$ is expressed in the pollen because of dominance. Styles emerge from female inflorescences of 'Wepster' in midseason and are fully receptive in mid-January. Pollenizers that shed compatible pollen in midseason and late-midseason are recommended. Recommended pollenizers are 'York' $\left(S_{2} S_{21}\right)$, 'Gamma' $\left(\mathrm{S}_{2} \mathrm{~S}_{10}\right)$ (Mehlenbacher and Smith, 2004), and OSU $880.027\left(\mathrm{~S}_{2} \mathrm{~S}_{15}\right)$. 'Yamhill' $\left(\mathrm{S}_{\underline{8}} \mathrm{~S}_{26}\right)$ is also a compatible pollenizer but its trees are much smaller than those of

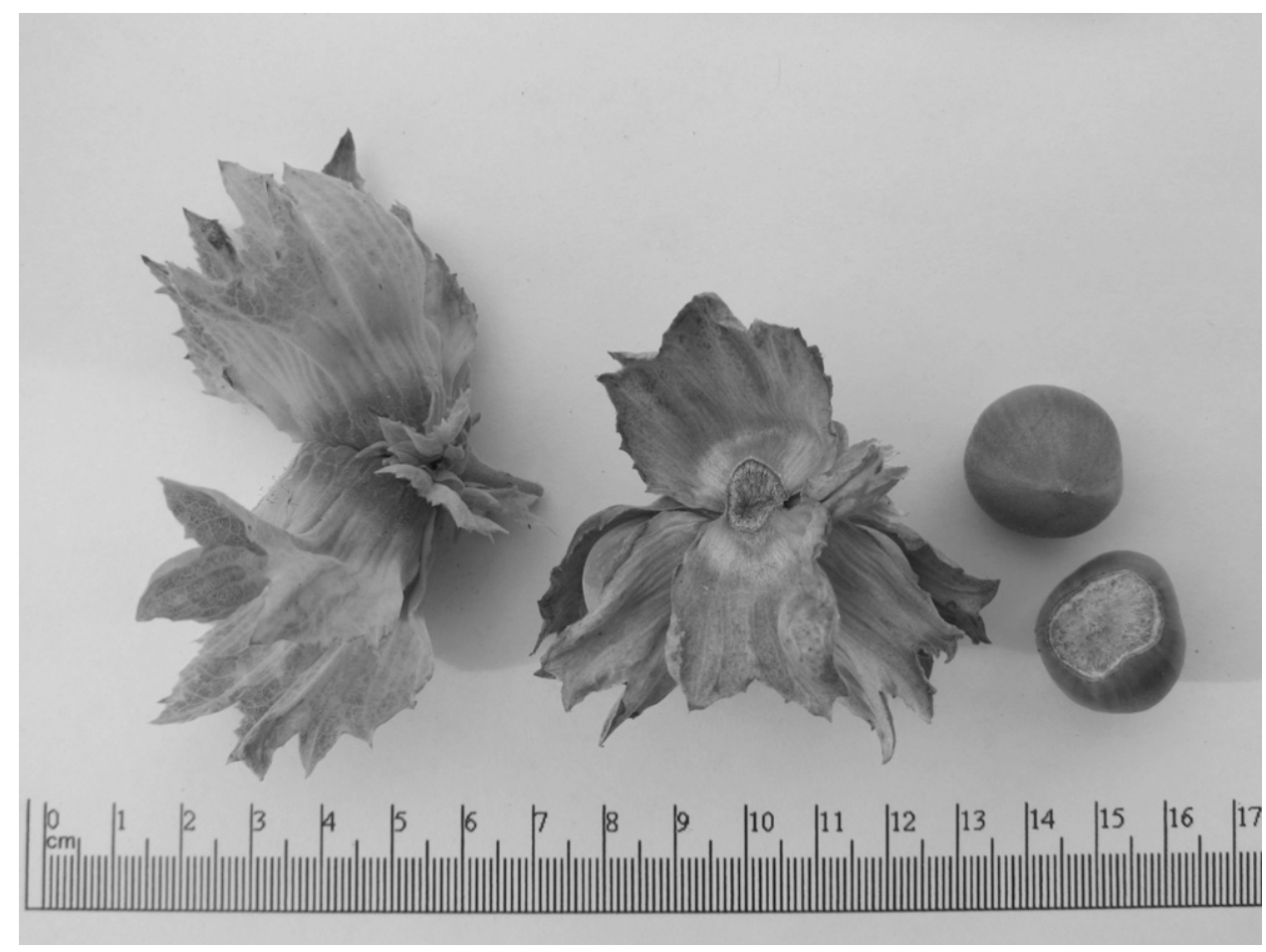

Fig. 3. Nuts and husks of 'Wepster' hazelnut. 


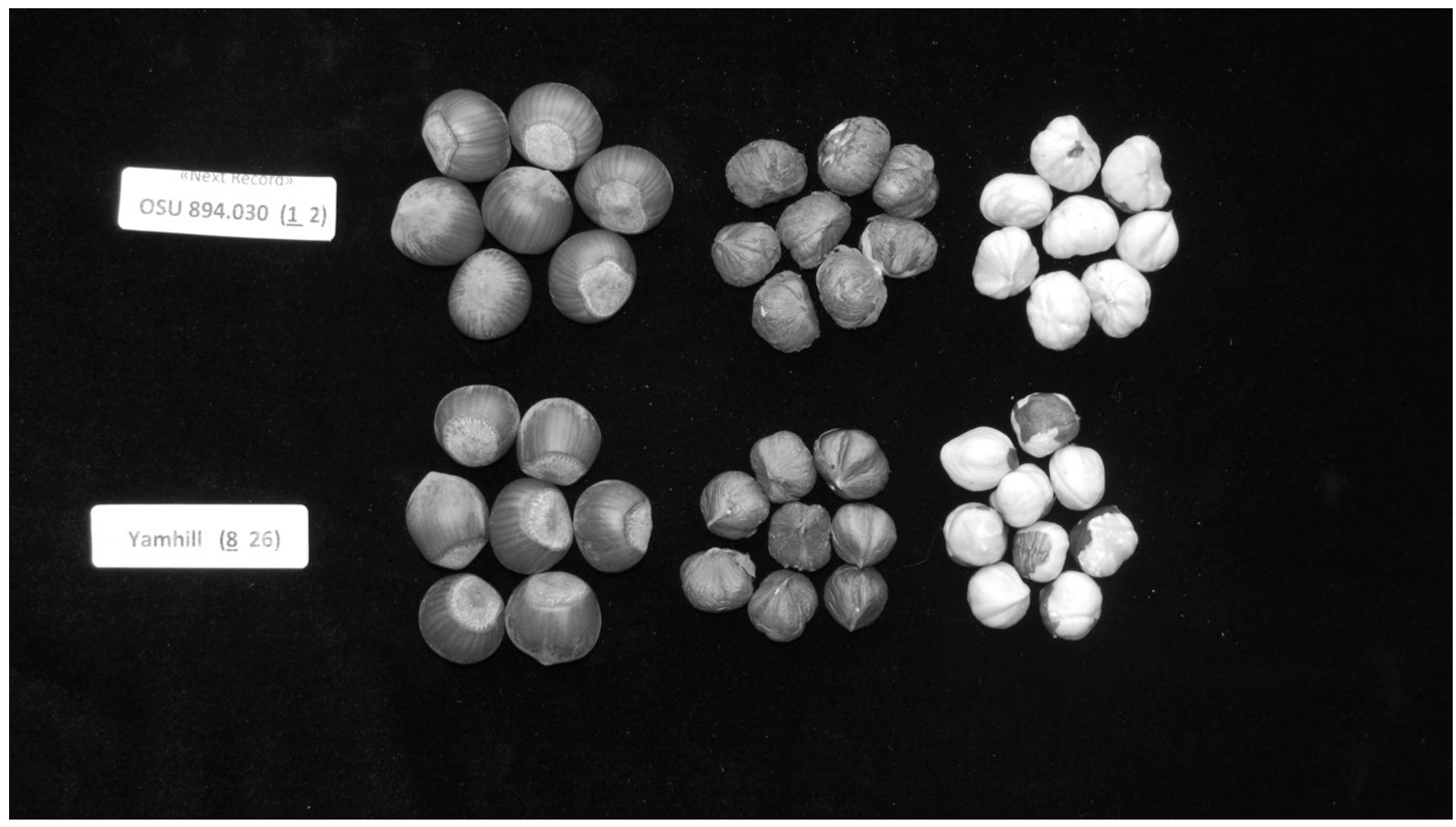

Fig. 4. Nuts, raw kernels, and blanched kernels of 'Wepster' (OSU 894.030, top) and 'Yamhill' (bottom) hazelnuts.

'Wepster'. In standard notation, the allele(s) expressed in the pollen are underlined. Pollen of 'Felix' and 'Jefferson' is compatible on 'Wepster' females, but their pollen is shed later than the ideal time. Pollen of 'Dorris', 'Sacajawea', and 'Barcelona' is incompatible on females of 'Wepster' because it expresses $\mathrm{S}_{1}$. Pollen of 'Tonda di Giffoni' is incompatible because it expresses $\mathrm{S}_{2}$. We encourage the planting of three pollenizers that shed pollen at different times during the period that female inflorescences are receptive to increase the likelihood that they will be pollinated.

Random amplified polymorphic DNA (RAPD) markers $152-800$ and 268-580 that flank the EFB resistance allele in 'Gasaway' (Mehlenbacher et al., 2004) are present in 'Wepster', indicating that it has a very high level of resistance. Additional RAPD markers linked to resistance are also present. 'Wepster' is heterozygous and transmits these markers to half of its seedlings. No trees of 'Wepster' in our trials developed cankers, but nearby trees of susceptible genotypes showed EFB cankers. 'Wepster' is suitable for planting in areas with high disease pressure. Greenhouse inoculations with Oregon isolate have not yet been conducted. The response of 'Wepster' to inoculation with other isolates of EFB from the eastern United States has not been tested. Susceptibility to bacterial blight caused by Xanthomonas campestris pv. corylina has not been quantified, but no trees in the two trials were affected. Nevertheless, copper sprays are recommended to minimize damage from this pathogen.
Susceptibility to bud mite (primarily Phytoptus avellanae Nal.) was rated in the first trial (Table 1) after leaf fall once per year for 5 years (Dec. 2008-12) on a scale of 1 (no blasted buds) to 5 (many blasted buds). The average ratings indicate a very high level of resistance for 'Wepster' (1.2), 'Jefferson' (1.1), and 'Yamhill' (1.1). Because blasted buds are very rare on 'Wepster', chemical applications should not be necessary to control bud mite.

Layers are generally vigorous and root easily and abundantly, comparable to those of 'Jefferson' and 'Barcelona'. In vitro cultures were established by the staff at the USDAARS National Clonal Germplasm Repository in Corvallis. These cultures have performed well with multiplication rates similar to other recently released cultivars. In Summer 2012, nurseries and commercial micropropagators were advised to increase 'Wepster' in preparation for its formal release. Many hazelnut orchards have been established in the Willamette Valley using micropropagated trees. In addition, a few 'Wepster' scions were provided to nurseries and growers for propagation by grafting. We expect trees to be available in limited quantities in the near future.

\section{Availability}

A U.S. Plant Patent application has been submitted for 'Wepster'. Nurseries interested in licensing agreements should contact Berry Treat, Senior Licensing Associate,
Office for Commercialization and Corporate Development, 312 Kerr Administration Building, Oregon State University, Corvallis, OR 97331-2140. Information on the release and small quantities of scion wood may be obtained from S.A. Mehlenbacher. Nurseries in other countries may request a license but may not sell trees during the 3 years after the release date.

\section{Literature Cited}

Mehlenbacher, S.A., A.N. Azarenko, D.C. Smith, and R. McCluskey. 2000. 'Lewis' hazelnut. HortScience 35:314-315.

Mehlenbacher, S.A., A.N. Azarenko, D.C. Smith, and R. McCluskey. 2001. 'Clark' hazelnut HortScience 36:995-996.

Mehlenbacher, S.A., A.N. Azarenko, D.C. Smith, and R.L. McCluskey. 2007. 'Santiam' hazelnut. HortScience 42:715-717.

Mehlenbacher, S.A., R.N. Brown, J.W. Davis, H. Chen, N.V. Bassil, D.C. Smith, and T.L. Kubisiak. 2004. RAPD markers lined to eastern filbert blight resistance in Corylus avellana. Theor. Appl. Genet. 108:651-656.

Mehlenbacher, S.A. and D.C. Smith. 2004. Hazelnut pollenizers 'Gamma', 'Delta', 'Epsilon' and 'Zeta' HortScience 39:1498-1499.

Mehlenbacher, S.A., D.C. Smith, and R. McCluskey. 2009. 'Yamhill' hazelnut. HortScience 44:845847.

Mehlenbacher, S.A., D.C. Smith, and R.L. McCluskey. 2011a. 'Jefferson' hazelnut. HortScience 46:662-664.

Mehlenbacher, S.A., D.C. Smith, R.L. McCluskey, and M.M. Thompson. 2011b. 'Tonda Pacifica' hazelnut. HortScience 46:505-508. 